\title{
Interpretation of quality of life scores from the St George's Respiratory Questionnaire
}

\author{
M. Ferrer*, C. Villasante", J. Alonso*, V. Sobradillo", R. Gabriel ${ }^{+}$, G. Vilagut*, J.F. Masa $^{\S}$, \\ J.L. Viejo ${ }^{f}$, C.A. Jiménez-Ruiz**, M. Miravitlles ${ }^{\# \#}$
}

Interpretation of quality of life scores from the St George's Respiratory Questionnaire. M. Ferrer, C. Villasante, J. Alonso, V. Sobradillo, R. Gabriel, G. Vilagut, J.F. Masa, J.L. Viejo, C.A. Jiménez-Ruiz, M. Miravitlles. (C)ERS Journals Ltd 2002.

ABSTRACT: The aim of the study was to obtain the general population norms for the St. George's Respiratory Questionnaire (SGRQ), a specific questionnaire for respiratory diseases.

The IBERPOC project was a cross-sectional study of representative samples of the general population aged between 40-69 yrs. The study sample was composed of 862 individuals. All participants considered as "probable cases" of chronic obstructive pulmonary disease (COPD) $(n=460)$ were eligible to complete the SGRQ and among the rest of the nonprobable COPD participants $(n=3,571), 10$ individuals from each defined age and sex group were eligible $(n=402)$. Weights were applied to restore general population representativity of the sample.

Mean forced expiratory volume in one second (FEV1) predicted was 89.4\% (SD=16.5\%; range: $16-131 \%$ ). Chronbach's alpha coefficients were $>0.7$ in the symptoms, activity and impact scales, and $>0.9$ in the overall scale. Symptom scale score was significantly higher among males $(11.6$ versus $7.8 ; \mathrm{p}<0.01)$ and activity scale score was significantly higher among females $(12.2$ versus $14.6 ; p=0.04)$. In a multiple linear regression model, respiratory diseases (asthma and COPD) and FEV1 \% over pred showed the strongest association with the SGRQ total score. Smoking, sex, age and education were independently associated with the total SGRQ score.

These results indicate that individuals from the general population presented some of the problems that are important when measuring health-related quality of life in respiratory patients, and provide St George's Respiratory Questionnaire norms, a useful method for interpreting the St George's Respiratory Questionnaire score in a given patient or study samples.

Eur Respir J 2002; 19: 405-413.

Health-related quality of life (HRQL) has become an important outcome in respiratory patients as proved by the development of several respiratory disease-specific HRQL questionnaires in recent years. Among them, the St. George's Respiratory Questionnaire (SGRQ) has become one of the most widely used instruments for assessing HRQL in respiratory patients, and has been translated into several languages [1-3]. The SGRQ has been used extensively in descriptive [4-9] and therapeutic evaluation studies (bronchodilator agents [10], oxygen therapy [11], psychotherapy [12] and respiratory rehabilitation [13]). However, this wide use is restricted mainly to the research setting. HRQL measurements have a number of drawbacks for use in a clinical practice. In fact, interpretation of HRQL results has been identified as one of the main barriers to generalizing their use in the clinical setting.

Clinicians have only recently been confronted with HRQL instruments and have not yet become familiar

\begin{abstract}
*Health Services Research Unit, Institut Municipal d'Investigació Mèdica, Barcelona, "Pneumology Dept, La Paz Hospital, Madrid, Respiratory Unit, Cruces Hospital, Baracaldo (Biscay), ${ }^{+}$Clinical Epidemiology Unit, La Princesa Hospital, Madrid, ${ }^{\S}$ Pneumology Unit, San Pedro de Alcántara Hospital, Cáceres, ${ }^{f}$ Pneumology Unit, General Yagüe Hospital, Burgos, **Pneumology Dept, La Princesa Hospital, Madrid and ${ }^{\# \#}$ Pneumology Dept, Vall d'Hebron Hospital, Barcelona, Spain.
\end{abstract}

Correspondence: M. Ferrer, Health Service Research Unit, Institut Municipal d'Investigació Mèdica, Carrer del Doctor Aiguader 80, E-08003 Barcelona, Spain.

Fax: 34932213237

E-mail: mferrer@imim.es

Keywords: Chronic obstructive pulmonary disease, quality of life, St George's Respiratory Questionnaire

Received: February 82001

Accepted after revision October 22001

The IBERPOC Study is funded by an unrestricted grant from Boehringer Ingelheim Spain S.A. with these results [14]. Comparisons with reference norms are a popular method of interpreting several clinical measures, such as general population-based norms for children's growth charts or healthy groupbased norms for spirometric values. Taking into account the familiarity with this strategy, it could be appropriate to facilitate the use of the SGRQ by clinicians. General population norms have been used for several HRQL questionnaires [15-19]. This approach allows clinicians to compare individuals or groups of patients with the distribution of scores [20]. If a 64-yr-old male who has received a score of 12 on the SGRQ is examined, it might be asked: "How does this score compare with expected values based on samples of other 64-yr-old males?" Gauged against a percentile distribution, this score can tell whether the patient is at the median $(50 \%$ with better scores and $50 \%$ with worse scores) or within the interquartile range (scores from 25-75\%) or below the fifth percentile ( $>95 \%$ with better score). The percentile 
technique, understood as a departure from these so-called norms, is easy to use and interpret.

The current study provides the first general population-norms for a respiratory-specific HRQL questionnaire. Data analysed here derive from the IBERPOC (Epidemiological study of chronic obstructive pulmonary disease in Spain) project, which was designed to estimate the prevalence of chronic obstructive pulmonary disease (COPD) in Spain. As described elsewhere [21, 22], IBERPOC is a general population survey of noninstitutionalized individuals aged between 40-69 yrs, from seven Spanish areas of different sizes and urban characteristics representing a total population of 236,412 persons. The aim of this article was to obtain reference norms, general population- and healthy group-based norms, for the SGRQ scores in order to facilitate its interpretation.

\section{Methods}

IBERPOC is a cross-sectional study of a noninstitutionalized population from seven Spanish areas of different sizes and urban characteristics. Details on the IBERPOC survey methods have been described previously [21, 22]. Briefly, a random sample proportionally stratified by sex and age (40-49, 50-59, 60-69 yrs) was drawn from the 1991 local census register in each site. Response rate was $69 \%$, from a total sample of 5,827 eligible individuals (932 refused the interview and 860 could not be contacted). A total of 4,035 participants were clinically assessed by a pneumologist. Forced expiratory volume in one second (FEV1) and forced vital capacity (FVC) were measured by using standard techniques and based on the results, participants were classified as probable or nonprobable cases of COPD. Predicted values were calculated according to the norms published by RocA et al. [23].

In order to avoid including patients with reversible airway obstruction due to asthma [22], a bronchodilator test was performed on all participants considered as probable cases of COPD. Following the European Respiratory Society criteria [24], diagnosis of COPD was reserved for subjects with FEV1/FVC \% over predicted $<88 \%$ in males and $<89 \%$ in females if they had never been diagnosed with asthma, and had a negative bronchodilator test or, in the case of a positive bronchodilator test, values after the challenge still had to fulfil the criteria for bronchial obstruction. From 464 probable cases of COPD, only 363 were diagnosed as COPD patients. All participants considered as probable cases of COPD were eligible to self-complete the Spanish version of the SGRQ. Four of them refused to complete it and finally, information from 460 probable COPD patients was obtained. Among the remaining 3,571 participants classified as nonprobable cases of COPD, 10 individuals from each stratum (defined by sex, age and centre) were systematically eligible to complete the SGRQ during the medical visit $(n=402)$.

\section{Instruments of measure}

The SGRQ is a standardized self-administered airways disease-specific questionnaire divided into three subscales: symptoms (eight items), activity (16 items), and impacts (26 items) [1, 25]. SGRQ scores were calculated using score calculation algorithms and missing data imputation (if total number of missing items was $\leqslant 10$ ) recommended by its developer (P.W. Jones, St George's Hospital Medical School, London, UK, personal communication). For each subscale and for the overall questionnaire, scores range from zero (no impairment) to 100 (maximum impairment).

A standard questionnaire was administered by the pneumologist to obtain information on age, sex, marital status, education, social class, smoking behaviour and respiratory diseases. Specifically, the participant was classified as asthmatic if they reported having been diagnosed with asthma by a physician. Information obtained on social class was based on an adaptation of the British Registrar General's classification [26].

\section{General population-based norms}

To estimate the SGRQ general population-based norms, a database was constructed including all of the 862 participants who completed the SGRQ. As a nonproportionally stratified sample design was applied (all probable cases of COPD were eligible to self-complete the SGRQ, while among the nonprobable cases of COPD only 10 individuals from each age and sex stratum were systematically eligible), weights that contain the inverse probability that the observation was included, due to the sampling strategy, were applied. Correcting the oversampling of probable COPD cases $(53 \%$ of the analysed sample), was conducted to make the samples' age, sex and prevalence of probable cases of COPD comparable and balanced with the corresponding distributions for Spain, as determined by the 1991 census. After weighting the percentage of probable COPD cases was $11 \%$, exactly the same percentage obtained in the whole sample of 4,035 individuals from the general population.

\section{Healthy group-based norms}

To obtain the healthy group-based norms, the following exclusion criteria were applied: 1) diagnosis of COPD $(n=363) ; 2)$ history of asthma $(n=82) ; 3)$ history of nonspecific chronic lung disease or FEV $1 \%$ over pred $<80 \%(n=110)$. From the 862 participants who completed the SGRQ, only 307 were included in the healthy group.

\section{Data analysis}

The general population database containing the 862 weighted participants with SGRQ information was used for all the analyses presented here except where the sample was constructed by using subsamples of 
Table 1. - Characteristics of the general population weighted sample

\begin{tabular}{|c|c|c|c|}
\hline Characteristics & All & M & $\mathrm{F}$ \\
\hline Patients $\mathrm{n}$ & 862 & 533 & 329 \\
\hline \multicolumn{4}{|l|}{ Sex } \\
\hline M & 48.5 & & \\
\hline $\mathrm{F}$ & 51.5 & & \\
\hline \multicolumn{4}{|l|}{ Age yrs } \\
\hline $40-49$ & 36.1 & 35.3 & 36.8 \\
\hline $50-59$ & 32.4 & 33.2 & 31.8 \\
\hline $60-69$ & 31.5 & 31.6 & 31.4 \\
\hline \multicolumn{4}{|l|}{ Education } \\
\hline High school or University & 42.5 & 48.8 & 65.3 \\
\hline Primary school or no education & 56.7 & 51.2 & 34.7 \\
\hline \multicolumn{4}{|l|}{ Social class (occupations) } \\
\hline I-II (professional/intermediate) & 18.1 & 23.2 & 13.1 \\
\hline III (skilled nonmanual) & 32.0 & 30.7 & 33.2 \\
\hline IV-V (manual) & 49.8 & 40.1 & 53.7 \\
\hline \multicolumn{4}{|l|}{ Smoking behaviour } \\
\hline Never smoker & 52.7 & 25.4 & 78.3 \\
\hline Former smoker & 24.1 & 41.5 & 7.8 \\
\hline Smoker >20 pack-yrs & 13.1 & 24.1 & 2.9 \\
\hline Smoker $\leqslant 20$ pack-yrs & 10.0 & 9.0 & 10.9 \\
\hline \multicolumn{4}{|l|}{ Respiratory diseases } \\
\hline COPD & 10.2 & 16.0 & 4.8 \\
\hline Asthma & 3.6 & 3.8 & 3.4 \\
\hline \multicolumn{4}{|l|}{ Spirometric results } \\
\hline $\mathrm{FVC} \mathrm{mL}$ & $3454.5 \pm 877.7$ & $4024.7 \pm 795.5$ & $2916.9 \pm 552.2$ \\
\hline FEV1 mL & $2578.6 \pm 726.4$ & $2959.5 \pm 762.8$ & $2219.5 \pm 459.7$ \\
\hline FVC \% over pred & $90.3 \pm 13.8$ & $87.0 \pm 13.8$ & $93.5 \pm 13.1$ \\
\hline FEV1 \% over pred & $89.5 \pm 16.5$ & $84.9 \pm 17.8$ & $93.7 \pm 13.8$ \\
\hline FEV $1 /$ FVC $\%$ over pred & $99.2 \pm 11.1$ & $96.6 \pm 12.0$ & $101.6 \pm 9.4$ \\
\hline
\end{tabular}

Data are presented as $\%$ or mean \pm SD unless otherwise stated. M: male; F: female; COPD: chronic obstructive pulmonary disease; FVC: forced vital capacity; FEV1: forced expiratory volume in one second. \#: social class based on an adaptation of the British Registrar General's Classification [26].

patients with COPD, participants with history of asthma and healthy group members.

Distribution characteristics, the percentage of patients with missing information, and reliability estimates were calculated for each SGRQ scale. Internal consistency of each scale was assessed by the Cronbach's alpha coefficient. Scaling success rates were computed as the percentage of items within a scale which had a greater correlation with their hypothesized scale, than with the other scales.

Analysis of variance and t-test were used to compare SGRQ scores between groups defined by sociodemographical or functional characteristics. Descriptive statistics of the SGRQ scores (including mean, standard deviation (SD) and percentiles) were calculated separately for six different age and sex groups. Multivariate linear regression was used to identify variables associated with total SGRQ score. Continuous variables such as age and FEV1 \% over pred were centred, that is, the variable included in the model was constructed by subtracting its mean value to the original variable. The regression coefficient obtained using this method was directly applicable to a theoretical subject with FEV1\% over pred and age, equal to the sample mean.

Reliability estimates of the SGRQ scale scores such as scaling success rate and Cronbach's alpha coefficient were calculated separately for probable and nonprobable cases of COPD, using the Multitrait
Analysis Program (MAP) [27], since it is not possible to apply weights with this package.

\section{Results}

Table 1 shows sociodemographical and lung function characteristics of the general population studied. Almost one-quarter reported being smokers, another one-quarter former smokers, and the other one-half of the sample nonsmokers. Mean FEV1 \% over pred was $89.5 \%(\mathrm{SD}=16.5 \%)$, ranging between $16-131 \%$. Differences by sex were significant: females were more educated, fewer were smokers, and suffered COPD less frequently. Distribution characteristics of the SGRQ scale scores are shown in table 2. As expected in a general population, since the majority of people have no respiratory problems, score distributions were clearly nonsymmetrical. For instance, on the activity scale, only one participant obtained the worst possible score, while $43 \%$ had the best. Less than $15 \%$ of individuals presented some missing item in the questionnaire, and missing score information was reduced to $1 \%$ of participants. High scaling success rate was achieved by most scales, ranging from 71.9-94.2. Cronbach's alpha coefficients were $>0.7$ in the symptoms, activity and impact scales and $>0.9$ in the overall scale.

Mean SGRQ scale scores in the general population 
Table 2. - Distribution characteristics and reliability estimates of the St George's Respiratory Questionnaire scales in the general population weighted sample

\begin{tabular}{lcccc}
\hline & Symptoms & Activity & Impacts & Overall \\
\hline Mean & 9.67 & 13.40 & 4.73 & 8.41 \\
SD & 13.24 & 17.63 & 9.92 & 11.33 \\
Observed range & $0-92.8$ & $0-100$ & $0-79.7$ & $0-83.4$ \\
\% with worst possible score (floor) & 0.0 & 43.5 & 0.0 & 0.0 \\
\% with best possible score (ceiling) & 41.2 & 7.6 & 59.5 & 21.1 \\
\% with missing data & 2.0 & 1.2 & 9.6 & 1.2 \\
\% with missing score & 1.2 & 0.90 & 0.89 & 1.2 \\
Cronbach's Alpha & & 0.84 & 0.87 & 0.95 \\
$\quad$ Probable case of COPD & 0.77 & 84.4 & 92.3 & 0.91 \\
$\quad$ Nonprobable case of COPD & 0.73 & 71.9 & 84.2 \\
Scaling success rate \%+ & & & 81.3 \\
$\quad$ Probable case of COPD & 87.5 & & 96.0 \\
$\quad$ Nonprobable case of COPD & & & \\
\hline
\end{tabular}

n=862. COPD: chronic obstructive pulmonary disease. ${ }^{\#}$ : percentage of individuals with at least one missing item; $\%$ percentage of individuals with missing score after handling missing data recommended by authors was applied; ${ }^{+}$: calculated separately for probable and nonprobable cases of COPD by using Multitrait Analysis Program because it is not possible to apply weights with this package.

weighted sample according to sociodemographical characteristics, smoking behaviour and FEV1 \% over pred are presented in table 3 . Symptoms scale score was significantly higher among males (11.6 versus $7.8 ; \mathrm{p}<0.01)$ and activity scale score was significantly higher among females (12.2 versus 14.6; $\mathrm{p}=0.04)$. SGRQ scores were significantly higher in older groups for all scales; total SGRQ scores were twice for individuals aged 60-69 yrs than for those aged $39-49$ yrs $(11.6$ versus $5.8 ; \mathrm{p}<0.01)$. Groups indicating lower education and social class also presented significantly higher scores for all scales. Smokers presented significantly higher scores only for symptoms and impacts scales. SGRQ scores also worsened in a statistically significant manner as FEV1 \% over pred decreased.

In the multiple linear regression model (table 4), respiratory diseases (asthma and COPD) and FEV1 impairment showed the strongest positive association with HRQL deterioration. The regression coefficient of the COPD term was not significant but remained in the model because interaction of COPD and FEV1 $\%$ over pred was statistically significant. Taking into account that FEV1 \% over pred was centred, this nonstandardized coefficient $(\mathrm{B}=-0.19)$ indicates FEV1 $\%$ over pred values lower than the observed mean $(90 \%)$, i.e. FEV1 impairment has a higher impact on HRQL of COPD patients. Interaction of age with asthma was also statistically significant, indicating that individuals suffering from asthma had greater worsening with age, when older than the observed mean (53.7 yrs). COPD and asthma showed a similar impact on the total SGRQ score if all the diseaserelated characteristics remained stable. For instance, an individual aged $50 \mathrm{yrs}$, with FEV1 \% over pred of 40 , suffering from COPD would increase the total score by 10.72 points $((1.22)+((40-90) \times(-0.19))$. If the individual suffered from asthma, the score would increase by 9.47 points $((13.91)+((50-53.7) \times(1.2))$.

Smoking was independently and positively associated with the total SGRQ score: participants who reported being current smokers showed around three points more (worse HRQL) than those who reported having never been smokers. Sex, age and education showed a statistically significant effect on the total SGRQ. Females presented two points more than males, and individuals with primary school or lower studies had 1.4 points more than individuals with a higher level of education. Finally, in contrast to what is observed in the bivariate analysis, differences in SGRQ total scores by social class disappeared and this variable was not included in the model.

Tables 5 and 6 show percentiles of the SGRQ scale scores by age to be used as general population reference norms for males and females, respectively. In general, younger age groups presented lower scores (better) in all the scales for both sexes. Impact was the scale that showed the steepest gradient by age. The easiest way for a clinician to use these results is to locate an individual patient's SGRQ score within the percentile distribution shown for that patient's age and sex. Hence, for a 64-yr-old, COPD male patient with an SGRQ total score of 12, one can find in the column corresponding to males with age of 60-69 yrs ( see third column of table 5 , in the subsection of total scores), that this score is located on percentile 60 . It means that $40 \%$ of the corresponding age-sex group were above this score (worse HRQL), and 60\% were below (better HRQL), indicating a low impact of COPD on the HRQL, because it was closest to the middle of the distribution. Whereas a 45-yr-old male patient with the same score would be above the 90th percentile (see first column of table 5, in the subsection of total scores), indicating a higher impact of COPD on the HRQL: at least $90 \%$ of the comparable individuals from the general population score better.

Table 7 shows SGRQ scores for males and females separately in the subsample of COPD patients, participants with history of asthma and healthy group members. Healthy females presented significantly higher (worse) scores than males for all the scales except symptoms. In contrast, no sex differences were observed between patients, except for symptoms scores, among those with COPD. Female COPD 
Table 3. - Mean St George's Respiratory Questionnaire scale scores by demographical and clinical characteristics in the general population weighted sample

Symptoms Activity Impacts Overall

\begin{tabular}{|c|c|c|c|c|}
\hline \multicolumn{5}{|l|}{ Sex } \\
\hline M & 11.62 & 12.17 & 5.23 & 8.60 \\
\hline $\mathrm{F}$ & 7.82 & 14.58 & 4.26 & 8.23 \\
\hline p-value & $<0.001$ & 0.043 & 0.15 & 0.63 \\
\hline \multicolumn{5}{|l|}{ Age yrs } \\
\hline $39-49$ & 7.97 & 9.33 & 2.69 & 5.78 \\
\hline $50-59$ & 8.74 & 13.48 & 4.55 & 8.19 \\
\hline $60-69$ & 12.54 & 17.95 & 7.23 & 11.61 \\
\hline $\mathrm{p}$-value & $<0.001$ & $<0.001$ & $<0.001$ & $<0.001$ \\
\hline \multicolumn{5}{|l|}{ Education } \\
\hline $\begin{array}{l}\text { High school } \\
\text { or more }\end{array}$ & 8.54 & 9.26 & 3.10 & 6.05 \\
\hline $\begin{array}{l}\text { Primary school or } \\
\text { no education }\end{array}$ & 10.45 & 16.53 & 6.02 & 10.20 \\
\hline $\mathrm{p}$-value & 0.03 & $<0.001$ & $<0.001$ & $<0.001$ \\
\hline \multicolumn{5}{|l|}{$\begin{array}{l}\text { Social class } \\
\text { (occupations) }^{\#}\end{array}$} \\
\hline $\begin{array}{l}\text { I-II (professional/ } \\
\text { intermediate) }\end{array}$ & 9.55 & 9.46 & 2.96 & 6.23 \\
\hline $\begin{array}{l}\text { III (skilled } \\
\text { nonmanual) }\end{array}$ & 7.92 & 10.19 & 3.14 & 6.27 \\
\hline IV-V (manual) & 10.29 & 15.93 & 5.64 & 9.79 \\
\hline p-value & 0.07 & $<0.001$ & $<0.001$ & $<0.001$ \\
\hline \multicolumn{5}{|l|}{ Smoking behaviour } \\
\hline Never smoker & 7.49 & 13.63 & 4.16 & 7.81 \\
\hline Former smoker & 9.58 & 13.19 & 5.50 & 8.69 \\
\hline $\begin{array}{l}\text { Smoker } \leqslant 20 \\
\text { pack-yrs }\end{array}$ & 12.99 & 11.58 & 3.38 & 7.76 \\
\hline $\begin{array}{c}\text { Smoker }>20 \\
\text { pack-yrs }\end{array}$ & 16.12 & 14.20 & 6.59 & 10.76 \\
\hline p-value & $<0.001$ & 0.74 & 0.04 & 0.09 \\
\hline \multicolumn{5}{|l|}{ FEV $1 \%$ over pred } \\
\hline FEV $1 \%_{1} \% 100$ & 5.39 & 9.33 & 2.33 & 5.14 \\
\hline $90 \leqslant$ FEV $1 \%<100$ & 8.23 & 9.17 & 2.80 & 6.01 \\
\hline $80 \leqslant$ FEV $1 \%<90$ & 9.12 & 13.94 & 4.68 & 8.47 \\
\hline FEV1 \% $<80$ & 16.20 & 21.14 & 9.27 & 14.30 \\
\hline p-value & $<0.001$ & $<0.001$ & $<0.001$ & $<0.001$ \\
\hline
\end{tabular}

M: male; F: female; FEV1: forced expiratory volume in one second. $n=862$. ${ }^{\#}$ : social class based on an adaptation of the British Registrar General's Classification [26].

patients scored significantly lower than male patients $(12.4$ versus 22.6, $\mathrm{p}<0.01)$. Although differences between COPD and asthma patients were observed, $95 \%$ confidence intervals are wide and they do not reach statistical significance.

\section{Discussion}

To the best of the authors' knowledge, this is the first study to obtain general population-based norms for a respiratory disease-specific HRQL questionnaire, and contrasts with the wide use of this interpretation strategy by other generic or diseasespecific HRQL questionnaires [15-19]. Researchers involved in respiratory disease-specific HRQL questionnaires have paid more attention to other interpretation approaches such as the definition of the minimal important difference $[25,28,29]$, which is mainly useful for the design and analysis of clinical trials. The findings of this study contribute to
Table 4.-Adjusted associations between St George's Respiratory Questionnaire total score (dependent variable) and respiratory disease-related variables in the general population weighted sample

\begin{tabular}{lccc}
\hline & B & Beta & p-value \\
\hline COPD & 1.22 & 0.03 & 0.40 \\
Asthma & 13.91 & 0.18 & $* *$ \\
FEV1 \% over pred & -0.13 & -0.21 & $* *$ \\
Interaction of COPD and & -0.19 & -0.11 & $* *$ \\
$\quad$ FEV1 \% over pred & & & \\
Smoking behaviour & & & \\
$\quad$ Never smoker & -0.08 & 0.00 & 0.91 \\
$\quad$ Former smoker & 2.60 & 0.09 & $* *$ \\
$\quad$ Smoker $\leqslant 20$ pack-yrs & 2.36 & 0.08 & 0.02 \\
$\quad$ Smoker >20 pack-yrs & 1.7 & 0.10 & $* *$ \\
Sex & 0.1 & 0.11 & $* *$ \\
Age & 1.4 & 0.08 & 0.02 \\
Education & 1.2 & 0.13 & $* *$ \\
Interaction of & & & $* *$ \\
$\quad$ age and asthma & 5.0 & & $*$ \\
Constant &
\end{tabular}

B: nonstandardized coefficient; Beta: standardized coefficient; COPD: chronic obstructive pulmonary disease; FEV 1 : forced expiratory volume in one second. $n=862$. \# : centred. Coefficient of determination: $\mathrm{R}^{2}=0.19$, adjusted $\mathrm{R}^{2}=0.18$. $* *: \mathrm{p}<0.01$

developing the understanding of the performance of the SGRQ in the general population, by providing summary statistics on the SGRQ scores for different subgroups. These summary statistics are based on a general population sample of 862 individuals, and provide the most reliable SGRQ norms available for the age groups studied.

Normative values based on the general population have been reported separately for males and females, and for age groups, because HRQL is influenced by age and sex $[15,18,19]$. SGRQ scores were significantly higher (worse) among older groups of the general population. This finding is not surprising, since many individuals from older age groups may suffer from respiratory diseases and/or other chronic conditions. Moreover, despite the assumption that SGRQ measures specifically the HRQL impact of respiratory diseases, it has been demonstrated that it may also reflect the impact of comorbidities on the HRQL of COPD patients [30]. As expected, taking into account differences in respiratory disease prevalence, the pattern of HRQL impairment showed differences by sex. Females presented fewer respiratory symptoms than males in the general population, and this difference disappeared among the healthy group. Females also showed higher activity scores (worse). However, this difference remains in the analysis restricted to the healthy group, indicating that sex differences in activity scores are partly independent of respiratory disease prevalence. Furthermore, supporting this finding, total SGRQ score was statistically higher (worse) among females after adjusting for COPD, asthma and disease-related variables. Differences in SGRQ scores by social class disappeared after adjustment for demographical and respiratory disease-related variables, but differences 
Table 5.-Percentiles (P) and means with SD of the St George's Respiratory Questionnaire (SGRQ) scale scores by age

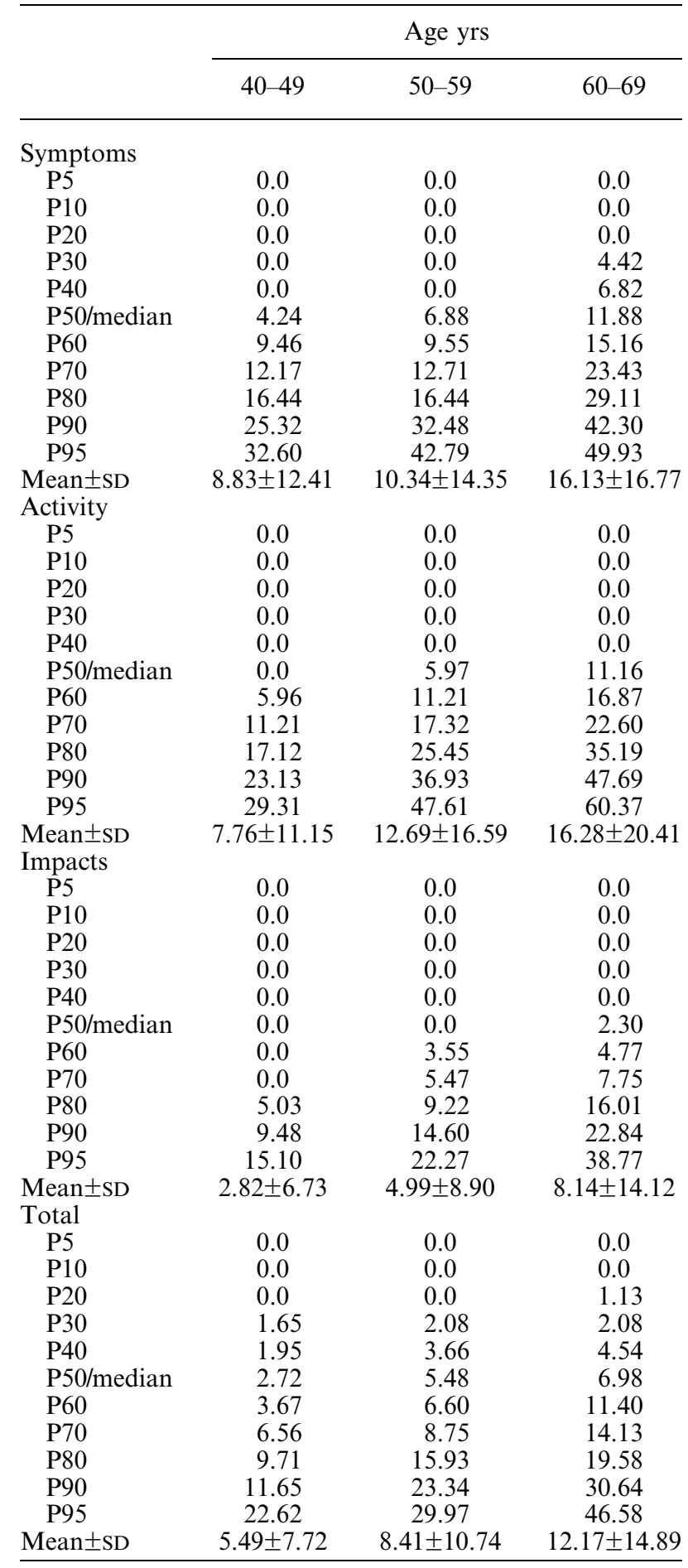

Data are presented as SGRQ scale scores unless otherwise stated. Males from the general population weighted sample $(\mathrm{n}=533)$.

by education level remained. All these results together with the metric characteristics obtained (low percentage of missing items and good reliability) contrast with the assumption that normative values are not appropriate for disease-specific questionnaires,
Table 6.-Percentiles (P) and means with SD of the St George's Respiratory Questionnaire (SGRQ) scale scores by age

\begin{tabular}{|c|c|c|c|}
\hline & \multicolumn{3}{|c|}{ Age yrs } \\
\hline & $40-49$ & $50-59$ & $60-69$ \\
\hline \multicolumn{4}{|l|}{ Symptoms } \\
\hline P5 & 0.0 & 0.0 & 0.0 \\
\hline P10 & 0.0 & 0.0 & 0.0 \\
\hline $\mathrm{P} 20$ & 0.0 & 0.0 & 0.0 \\
\hline P30 & 0.0 & 0.0 & 0.0 \\
\hline P40 & 0.0 & 0.0 & 2.32 \\
\hline P50/median & 4.42 & 4.24 & 4.42 \\
\hline P60 & 6.75 & 8.80 & 8.13 \\
\hline P70 & 8.80 & 9.69 & 9.54 \\
\hline P80 & 12.17 & 14.08 & 14.29 \\
\hline P90 & 18.79 & 19.28 & 28.18 \\
\hline P95 & 39.21 & 23.76 & 44.79 \\
\hline Mean \pm SD & $7.24 \pm 10.85$ & $7.09 \pm 8.88$ & $9.24 \pm 13.43$ \\
\hline \multicolumn{4}{|l|}{ Activity } \\
\hline P5 & 0.0 & 0.0 & 0.0 \\
\hline P10 & 0.0 & 0.0 & 0.0 \\
\hline $\mathrm{P} 20$ & 0.0 & 0.0 & 0.0 \\
\hline P30 & 0.0 & 0.0 & 0.0 \\
\hline P40 & 0.0 & 0.0 & 5.96 \\
\hline P50/median & 5.25 & 6.21 & 12.19 \\
\hline P60 & 11.41 & 12.27 & 17.84 \\
\hline P70 & 17.12 & 23.28 & 29.31 \\
\hline P80 & 20.28 & 29.31 & 41.61 \\
\hline P90 & 35.17 & 35.47 & 47.69 \\
\hline P95 & 41.08 & 54.42 & 67.02 \\
\hline Mean \pm SD & $10.81 \pm 13.99$ & $14.29 \pm 17.43$ & $19.36 \pm 22.62$ \\
\hline \multicolumn{4}{|l|}{ Impacts } \\
\hline P5 & 0.0 & 0.0 & 0.0 \\
\hline P10 & 0.0 & 0.0 & 0.0 \\
\hline P20 & 0.0 & 0.0 & 0.0 \\
\hline P30 & 0.0 & 0.0 & 0.0 \\
\hline P40 & 0.0 & 0.0 & 0.0 \\
\hline P50/median & 0.0 & 0.0 & 0.0 \\
\hline P60 & 0.0 & 3.55 & 3.55 \\
\hline P70 & 1.90 & 3.55 & 4.06 \\
\hline P80 & 4.06 & 7.17 & 8.35 \\
\hline P90 & 10.67 & 10.64 & 15.43 \\
\hline P95 & 14.38 & 20.43 & 43.03 \\
\hline Mean \pm SD & $2.62 \pm 5.63$ & $4.10 \pm 7.64$ & $6.38 \pm 13.25$ \\
\hline \multicolumn{4}{|l|}{ Total } \\
\hline P5 & 0.0 & 0.0 & 0.0 \\
\hline P10 & 0.0 & 0.0 & 0.0 \\
\hline $\mathrm{P} 20$ & 0.0 & 0.0 & 1.28 \\
\hline P30 & 0.80 & 1.78 & 2.17 \\
\hline P40 & 2.17 & 2.82 & 3.34 \\
\hline P50/median & 3.75 & 4.44 & 4.26 \\
\hline P60 & 5.81 & 8.35 & 9.37 \\
\hline P70 & 7.38 & 10.92 & 13.28 \\
\hline P80 & 10.95 & 13.04 & 17.76 \\
\hline P90 & 15.40 & 17.93 & 25.96 \\
\hline P95 & 21.04 & 31.46 & 49.99 \\
\hline Mean \pm SD & $6.09 \pm 7.41$ & $7.97 \pm 9.35$ & $11.05 \pm 14.83$ \\
\hline
\end{tabular}

Data are presented as SGRQ scale scores unless otherwise stated. Females from the general population weighted sample $(n=329)$.

because they can be used validly only in people suffering from the disease.

General population-based reference norms are the approach used for height and weight in the assessment of paediatric growth, with both diseased and healthy 
Table 7. - Distribution characteristics of the St George's Respiratory Questionnaire (SGRQ) scores according to sex in the subsample of chronic obstructive pulmonary diseas (COPD) patients, participants with history of asthma and healthy group

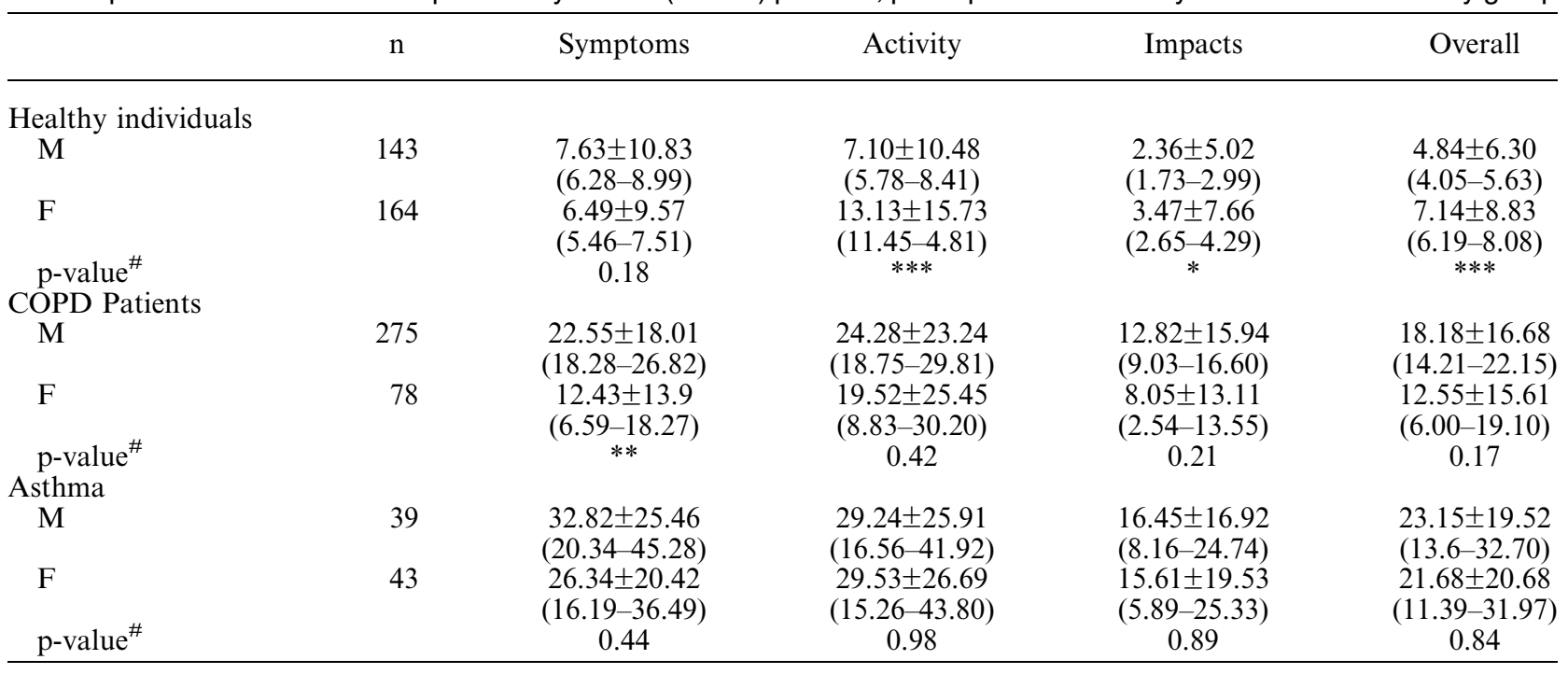

Data are presented as mean \pm SD $\left(95 \%\right.$ confidence interval) unless otherwise stated. M: male; F: female. ${ }^{*}$ : comparison between SGRQ score from $\mathrm{M}$ and $\mathrm{F}$. *: $\mathrm{p}<0.05 ;{ }^{* *}: \mathrm{p}<0.01 ; \mathrm{p}<0.001$.

persons being represented in the reported distribution. The use of percentiles to describe the distribution does not require assumptions of normal distributions and makes it possible to interpret the SGRQ scores: 1) provides information on the amount of HRQL impairment of an individual or a group by comparing the score obtained, with the distribution of scores of the corresponding population; 2) difference in percentile position may help to determine the size of score differences, observed either in a patient over time or between patients. Following the example used in the results section (two males with exactly equal total SGRQ score, 12 points, but different age); the wide distance observed between these two COPD patients in the general population norms (30 percentiles, from percentile 60 for the 64 -yr-old patient to percentile 90 for the 45-yr-old patient) clearly suggests a different HRQL level despite having the same score.

Reference norms used in biological parameters, such as serum creatinine or FEV1, are obtained from samples composed only of healthy individuals. Describing the healthy population by using percentiles makes no sense because its distribution is very narrow (the value of most percentiles would be zero) and would not be informative. However, comparisons with healthy population-based norms could be useful to interpret HRQL scores, by using them mainly as the reference for the minimum level of impairment. Although the SGRQ is constructed in such a way that a score of zero indicates no HRQL impairment, even persons who do not suffer from respiratory diseases will very seldom score the minimum on all items. Following again the example described earlier of 12 points on the SGRQ total score, compared with the healthy male group it is around seven points higher than the mean of 4.84 points. Therefore, a simple comparison between a patients' score and zero (the minimum attainable score) will overestimate the impairment on HRQL. Furthermore, for the 64-yr-old COPD male patient in the present study, despite 12 being statistically higher than $4.84(95 \%$ confidence interval (CI): 4.05-5.63), the position almost in the middle of the distribution of his age and sex corresponding to the general population (percentile 60) suggests a low impact of COPD on HRQL. Thus, information from percentile distributions of the general population and healthy group-based norms is complementary for most interpretative purposes.

This study has some aspects on generalization that merit comment. First, general population representativeness, because the participation rate was acceptable $(69 \%)$ but not $100 \%$. Nonrespondent individuals are usually the healthiest, and thus, if scores presented here were different from the "true norm", they might be unrealistically high. However, statistical weights were applied to bring the age, sex and prevalence of probable cases of COPD distributions into balance with those of the general population to minimize this effect. Second, because this study included only individuals aged from 40-69 yrs, no reference data were obtained for individuals outside this range.

An important issue regarding the reference scores presented herein is whether they are only useful for comparisons with Spanish populations or are more widely applicable. Considering that percentiles were stratified by age and sex, they are useful for comparisons with different populations presenting whatever age or sex structure. Although no large differences by country in reference scores are expected they are uncertain. In fact, SGRQ scores reported by SPENCER et al. [31] for 74 English subjects with no history of respiratory disease were quite similar to those observed in the present study for comparable healthy individuals from Spain, except for symptoms. Significantly lower symptom scores were obtained for healthy Spanish compared with English subjects (12; 95\% CI: 9-15). This difference could reflect a true difference by country in terms of respiratory 
symptoms. It is important to consider the possible lack of comparability with the English questionnaire for the symptom items, despite the validity study of the Spanish version suggesting that it was conceptually equivalent to the original [2].

Notwithstanding such limitations, this work examines the distribution of age and sex with the St George's Respiratory Questionnaire score and presents a useful method for interpreting a St George's Respiratory Questionnaire score against reference standards based on a general population study. The use of percentiles as a way of evaluating the range of scores for age and sex categories gives the clinician and researcher a method of comparison that takes into account these factors. It also considers to what extent age, sex and related variables are determinants of either health-related quality of life impairment, or the respiratory diseases. The results of this study indicate that the individuals from the general population shared some of the complaints which are relevant when measuring health-related quality of life in respiratory patients, showing that the use of the minimum theoretical score of a respiratoryspecific health-related quality of life questionnaire, as a point of reference or a "true zero", may be inappropriate. The distributions presented here provide useful reference values for clinicians or investigators who use the St George's Respiratory Questionnaire to assess the health-related quality of life of their patients or study samples.

Acknowledgements. The authors would like to thank the following participating bodies. Organizing institution: Sociedad Española de Neumología y Cirugía Torácica (SEPAR); Área de Trabajo sobre Insuficiencia Respiratoria y Trastornos del Sueño (IRTS). Sponsoring Institution: Boehringer Ingelheim España, S.A. Scientific committee: SEPAR: V. Sobradillo Peña, Unidad de Patología Respiratoria, Hospital de Cruces, Baracaldo (Vizcaya); L. Fernández-Fau, Servicio de Cirugía Torácica, Hospital Universitario de la Princesa, Madrid; C. Villasante Fernández-Montes, Servicio de Neumología, Hospital La Paz, Madrid; J.F. Masa Jiménez, Unidad de Neumología, Hospital San Pedro de Alcántara, Cáceres; J.L. Viejo Bañuelos, Servicio de Neumología, Hospital General Yagüe, Burgos; C.A. Jiménez Ruiz, Servicio de Neumología, Hospital Universitario de la Princesa, Madrid; Asociación Española para el Desarrollo de la Epidemiología Clínica AEDEC): R. Gabriel Sánchez, Unidad de Epidemiología Clínica, Hospital Universitario de la Princesa, Madrid. Fieldwork Coordinator: M. Miravitlles, Pharma Consult Services, S.A.,Barcelona. Collaborating Institutions: Sibel S.A., Unidad de Investigación en Servicios Sanitarios IMIM (Barcelona), Soikos, Centre d'Estudis en Economia de la Salut i de la Política Social S.L. (Barcelona). Coordinators and local investigators: Coordinator SEPAR (Asturias): J. Martínez González del Rio, Servicio de Neumología, Hospital de Asturias, Oviedo, Investigator: J.A. Gullón Blanco; Coordinator SEPAR (Burgos): J.L. Viejo Bañuelos, Investigator: L. Lázaro Asegurado; Coordinator SEPAR (Cáceres): J.F. Masa Jiménez,
Investigator: L. Ramos Casado; Coordinator SEPAR (Madrid): C. Villasante FernándezMontes, C.A. Jiménez Ruiz, Investigator: A. Dorgham; Coordinator SEPAR (Sevilla): J. Castillo Gómez, Servicio de Neumología, Hospital Virgen del Rocío, Investigator: J. Fernández Guerra, F. Valenzuela, Coordinator SEPAR (Manlleu): J. Serra-Batlle, Servicio de Neumología, Hospital General de Vic, Investigator: J. Casadevall Escayola; Coordinator SEPAR (Vizcaya): V. Sobradillo Peña, Investigator: P. Gil Alaña.

\section{References}

1. Jones PW, Quirk FH, Baveystock CM, Littlejohns P. A self-complete measure of health status for chronic airflow limitation. Am Rev Respir Dis 1992; 145: 13211327.

2. Ferrer $\mathrm{M}$, Alonso J, Prieto $\mathrm{L}$, et al. Validity and reliability of the St George's Respiratory Questionnaire after adaptation to a different language and culture: the Spanish example. Eur Respir J 1996; 9: $1160-1166$.

3. Gallefoss F, Bakke PS, Kjasgaard P. Quality of life assessment after patient education in a randomized controlled study on asthma and chronic obstructive pulmonary disease. Am J Respir Crit Care Med 1999; 159: 812-817.

4. Okubadejo AA, Jones PW, Wedzicha JA. Quality of life in patients with chronic obstructive pulmonary disease and severe hypoxaemia. Thorax 1996; 51: 44 47.

5. Ketelaars CAJ, Schlösser MAG, Mostert R, Huyer Abu-Saad H, Halfens RJG, Wouters EFM. Determinants of health-related quality of life in patients with chronic obstructive pulmonary disease. Thorax 1996; 51: 39-43.

6. Renwick DS, Connolly MJ. Impact of obstructive airways disease on quality of life in older adults. Thorax 1996; 51: 520-525.

7. Wilson CB, Jones PW, O'Leary CJ, Hansell DM, Cole PJ, Wilson R. Effect of sputum bacteriology on the quality of life of patients with bronchiectasis. Eur Respir J 1997; 10: 1754-1760.

8. Shoup R, Dalsky G, Warner S, et al. Body composition and health-related quality of life in patients with obstructive airways disease. Eur Respir J 1997; 10: $1576-1580$.

9. Osman LM, Godden DJ, Friend JA, Legge JS, Douglas JG. Quality of life and hospital re-admission in patients with chronic obstructive pulmonary disease. Thorax 1997; 52: 67-71.

10. Jones PW, Bosh TK. Quality of life changes in COPD patients treated with salmeterol. Am J Respir Crit Care Med 1997; 155: 1283-1289.

11. Okubadejo AA, Paul EA, Jones PW, Wedzicha JA. Does long-term oxygen therapy affect quality of life in patients with chronic obstructive pulmonary disease and severe hypoxaemia? Eur Respir J 1996; 9: 23352339.

12. Eiser N, West C, Evans S, Jeffers A, Quirk F. Effects of psychotherapy in moderately severe COPD: a pilot study. Eur Respir J 1997; 10: 1581-1584.

13. Ketelaars CA, Abu-Saad HH, Schlosser MA, Mostert $\mathrm{R}$, Wouters EF. Long-term outcome of pulmonary 
rehabilitation in patients with COPD. Chest 1997; 112: 363-369.

14. Ware JE, Keller SD. Interpreting general health measures. In: Spilker B, ed. Quality of Life and Pharmaeconomics in Clinical Trials. 2nd ed. Philadelphia, Lippincott-Raven Publishers, 1996; pp. 445-460.

15. Ware JE Jr, Snow KK, Kosinski M, Gandek B. Health Survey: Manual and Interpretation Guide. The Health Institute: New England Medical Center, Boston, MA, USA, 1993.

16. Crum RM, Anthony JC, Bassett SS, Folstein MF. Population-based norms for the Mini-Mental State Examination by age and educational level. JAMA 1993; 269: 2386-2391.

17. Alonso J, Regidor E, Barrio G, Prieto L, Rodríguez C, de la Fuente L. [Population-based reference values for the Spanish version of the Health Survey SF-36] Valores poblacionales de referencia de la versión española del Cuestionario de Salud SF-36. Med Clin 1998; 111: 410-416.

18. Forsberg C, Bjorvell H. Swedish population norms for the GHRI, HI and STAI-state. Qual Life Res 1993; 2 : 349-356.

19. Klee M, Groenvold M, Machin D. Quality of life of Danish women: population-based norms of the EORTC QLQ-C30. Qual Life Res 1997; 6: 27-34.

20. Feinstein AR. The range of normal. In: Feinstein AR, ed. Clinical Epidemiology: The Architecture of Clinical Research. Philadelphia, Saunders Co., 1985; 674.

21. Miravitlles M, Sobradillo V, Villasante C, et al. [Epidemiological study of chronic obstructive pulmonary disease in Spain (IBERPOC): recruitment and field work] Estudio epidemiológico de la EPOC en España (IBERPOC): reclutamiento y trabajo de campo. Arch Bronconeumol 1999; 35: 152-158.

22. Sobradillo V, Miravitlles M, Gabriel R, et al. Geographical variations in prevalence and underdiagnosis of COPD. Results of the IBERPOC multicentre epidemiological study. Chest 2000; 118: 981-989.

23. Roca J, Sanchis J, Agustí-Vidal A. Spirometric reference values from a Mediterranean population. Bull Eur Physiopathol Respir 1986; 22: 217.

24. Siafakas NM, Vermeire NB, Pride P, et al. Optimal assessment and management of chronic obstructive pulmonary disease (COPD). A consensus statement of the European Respiratory Society (ERS). Eur Respir J 1995; 8: 1398-1420.

25. Jones PW, Quirk FH, Baveystock CM. The St George's Respiratory Questionnaire. Respir Med 1991; 85: Suppl. B, 25-31.

26. Domingo-Salvany A, Marcos J. Propuesta de un indicador de la "clase social" basado en la ocupación. Gac Sanit 1989; 3: 320-326.

27. Hays RD, Anderson R, Carson S, Ware JE. User's guide for the Multitrait Analysis Program (MAP). N-2876-RC. The RAND Corp., Santa Monica, CA, USA, 1988.

28. Juniper EF, Gordon GH, Willan A, Griffith LE. Determining a minimal important change in a diseasespecific quality of life questionnaire. $J$ Clin Epidemiol 1994; 47: 81-87.

29. Redelmeier DA, Guyatt GH, Goldstein RS. Assessing the minimal important difference in symptons: a comparison of two techniques. $J$ Clin Epidemiol 1996; 49: 1215-1219.

30. Ferrer M, Alonso J, Morera J, et al. Chronic obstructive pulmonary disease stage and healthrelated quality of life. The Quality of Life of Chronic Obstructive Pulmonary Disease Study Group. Ann Intern Med 1997; 127: 1072-1079.

31. Spencer S, Calverley PMA, Sherwood Burge P, Jones PW, on behalf of the ISOLDE. Health status deterioration in patients with chronic obstructive pulmonary disease. Am J Respir Crit Care Med 2001; 163: 122-128. 